\title{
Critical Reflections on the Surface, Pedagogical and Epistemological Features of the Design Studio under the "New Normal" Conditions
}

\author{
Derya Yorgancioğlu \\ Özyeğin University, Faculty of Architecture and Design, Istanbul, Turkey
}

Received: May 28th 2020, Accepted: June 6th 2020

Refer: Yorgancioglu, D., (2020), Critical Reflections on the Surface, Pedagogical and Epistemological Features of the Design Studio under the "New Normal" Conditions, Journal of Design Studio, V.2, N.1, pp 25-36,

ORCID: 0000-0002-5583-3515

DOI: $10.46474 /$ jds. 744577 https://doi.org/10.46474/jds.744577

\begin{abstract}
This study aims to make a critical reading on the constraints and potentials that emerge through the transition from face-to-face to screen-to-screen teaching and learning experiences in design education during the COVID-19 pandemic. By making a critical reading of current discussions, mostly in narrative surveys, on architectural design education, it is attempted to re-contextualize the emerging concepts of the remote teaching and learning to the broader context of design studio pedagogy literature. The theoretical framework of the study is based on the model developed by Shaffer (2003) regarding the three main elements of the design studio pedagogy as (1) "surface structures", (2) "pedagogical forms" and (3) "epistemological principles." The study revealed that the current situation, on the one hand, opened the ways for us to test "new" tools, methods and experiences of teaching and learning, and on the other hand, allowed us to better understand the potentials and well-functioning aspects of the "existing" pedagogical models. Rather than reducing the discussions on remote teaching and learning to a 'technology-driven' paradigm change in design education, future research should focus on the effects of changing pedagogical tools and practices on the manifold dimensions of 'human learning', which in turn will have implications for the epistemology of design pedagogy.
\end{abstract}

Keywords: COVID-19, architectural design education, design studio pedagogy, remote teaching, new normal, human element.

\section{Introduction}

From March 2020 on, the lockdown resulted from the COVID-19 pandemic has created tremendous impact on various fields of life; the field of higher education was not an exception. This impact manifested itself unexpectedly, and the higher education area has entered into a process of new adjustments. Adjustment efforts also continue in the field of architectural education and especially architectural design education. The studio tutors are trying to find their ways through the quick transition from formal education at the campus to remote teaching at home. While the design reviews have altered in scope and format, we're trying to discover the procedures of digital platforms, which some of us have recently heard, to serve for design reviews in synchronous and asynchronous setups. For the field of architectural design education that dwell on a studio tradition spanning more than a century, the obligatory removal of the physical studio environment and of the inter-subjective communication generated through 'design crits', is transforming the ongoing teaching and learning practices and experiences. In this environment that is defined as the "new normal," the technological problems such as lack of computers, lack of reliable Internet access or the limited licenses for the universities (archinet.com), are merging with the emotional and psychological tensions both for instructors and students arising from the change of established pedagogical approaches and 
commitments. The emotional and psychological problems vary from the feeling of anxiety due to the uncertainty of post-pandemic environment, the inability of students to focus on their projects on the pandemic period and the feeling of loneliness resulted from social isolation, to the fact that they do not have any sensory or spatial escape in online teaching (archinet.com). What is more, for some students even sitting in front of the computer and expressing themselves to the camera can be a source of anxiety itself (Acar, 2020). While we're still trying to define this ongoing process, scenarios about "post-pandemic future" of higher education are already drawn. Some scenarios are dwelled on the commitment of "big tech's entrée into higher education" (James D. Walsh, May 2020) and how this situation will support the cooperation between education and industry for inline education (Patricia Morton, April 2020). Additionally, there is a consideration that, once the potential inequities regarding Internet access is resolved, the teaching and learning practices to be carried out on virtual platforms will support equity, diversity, flexibility and mobility in design education (Jonathan Massey, April 2020). There is also an optimistic idea that this new situation would support "“self-directed study" for the students (Barbara Penner, April 2020).

The definitions of what we're experiencing today is varied; while some scholars address a shift toward "online teaching", "online learning" or "distant learning" (Carlo D'Alesio (April 2020) a more critical perspective underscores an "emergency remote teaching/instruction" or "emergency remote learning" as the best definition of our ongoing experience in architectural design education (Brett Milligan, April 2020; Andrew Herscher, April 2020; Kadambari Baxi, April 2020). Fred Scharmen (April 2020) notes: "Online teaching requires far more structure and planning than any of us have had the capacity to provide. This is better considered as crisis management and harm reduction. We are in a reactive mode, and the best we can do is to try to avoid causing any more damage." While the design education practices that we're trying to adjust ourselves in the pandemic environment are defined as "new", the practices we experienced few months ago are already defined as "old"; there is an emerging view that nothing will be the same anymore.

Evidently, the changing conditions resulted by the COVID-19 pandemic compel us to question several aspects of the mainstream architectural education; however, will this situation transform the whole pedagogy of design studio education? Is something really "new" replacing the "old"? This situation that is common all over the world opens the way for us to test new tools and methods of communication and teaching/learning practices; the tools previously used as tools of representation and simulation are now serving as pedagogical tools. Yet, is it possible to say that the established pedagogical models will be completely redundant? How realistic is it to model the design education of the 'future' while we're still trying to define the conditions of 'now'?

The technological dimension of the ongoing remote teaching process has been, to a great extent, solved with the tools currently used, and these tools will be developed according to the data to be obtained from our experiences. Providing more access to these digital tools by the students and the instructors is a critical issue to be solved and there is an inequality of access especially for students living in rural areas. However, the researches should focus more on the effects of the use of digital tools in teaching and learning practices on the "human" dimension of the design pedagogy and on human learning. The changes in the nature of learning experiences and the transmission of knowledge bring forth pedagogical dilemmas: what kinds of knowledge, what kinds of doing, what kinds of creativity are at issue? How will the tacit knowledge embedded in subjective creative endeavor and in inter-subjective communication in the conventional design studio be influenced? What will be effects of new digital platforms (or the new usage patterns of existing digital platforms) and new forms of exchanges on the pedagogy and culture of the design studio? These questions can hardly be answered now, since it will take time to observe the effects of ongoing remote teaching/learning 
in different contexts, to analyze them in order to unfold their positive and negative aspects for design education. Therefore, it is still early to make suggestions about what architectural education and design education will transform into in the near future.

This study aims to make a critical reading on the constraints and potentials that emerge through the transition from face-to-face communication to screen-to-screen on the basis of design studio pedagogy. Therefore, by reviewing the current discussions, mostly in narrative surveys, in national and international circles of architectural education and design education, it is attempted to be re-contextualize the emerging concepts of the remote teaching and learning to the broader context of design pedagogy literature. The model regarding the three main elements of the design studio pedagogy developed by Shaffer (2003) - (1) "surface structures", (2) "pedagogical forms" and (3) "epistemological principles" - constitutes the theoretical framework of this study.

\section{Design Studio Pedagogy}

Shaffer (2003) explains the model based on the analysis of the Oxford Studio as his case study as follows:

\begin{abstract}
"In the Oxford Studio, surface features such as time, space, access to experts, and media of expression came together to form a structure organized to support specific learning activities. That is, the learning activities provided consistent and coordinated relationships among the surface features of the environment. Similarly, learning activities came together to form a pedagogy by virtue of the fact that they were arranged to convey a particular approach to understanding based on the properties of architectural ideas. The understanding of architectural ideas, in turn, became a coherent epistemology when instantiated in the structure and pedagogy of the Oxford Studio." (Shaffer, 2003, p. 27)
\end{abstract}

Gray (2016, p. 272) notes, in Shaffer's (2003) model while the surface structures refer to "the physical, readily apparent elements of what comprises a studio environment", the pedagogical forms are more related with the "instructional landscape of the studio" that derive from the ways the teaching and learning activities peculiar to design education are performed by the tutor and the students; and finally the epistemological principles are made manifest through the "'hidden curriculum' of how a student's progress is judged, what kinds of behaviors are rewarded and, ultimately, what the discipline values and/or rewards." These three features of the Oxford Studio model offered by Shaffer (2003) point to the basic components of the design studio pedagogy in general, which is complex and multilayered in nature. It necessitates the active engagement of both the tutor and the students, and offers a holistic experience of learning and of meaning making for all actors. In terms of the teaching and learning strategies employed by the tutors and the students, the design studio supports the students' abilities with regard to "knowing about design, being able to design, and becoming a professional" (Crowther, 2013, p. 20 ), which signify the three main features of "signature pedagogy" as defined by Shulman (2005).

\subsection{The "Surface Structures" of Design Studio}

The primary change in our transition to remote teaching in architectural design education at the COVID-19 pandemic occurred in the removal of physical studio environment, which resulted in the lack of embodied encounters. As underlined by Shaffer (2003), the physical features of the design studio influence the modes of interaction between tutor-student and student-student. In the so-called "new normal" conditions, the physical space of the studio, as an element of the "surface structure features" (Shaffer 2003), is replaced with the rooms of our homes. While the physical studio environment was a 'shared space' structured through the social interactions, the instructor and each student partake in the virtual design crit platforms from their 'personal spaces.' Robin Tremblay-McGaw (April 2020) explains: "Academic education is relocating to bedrooms, home offices, kitchen tables, couches, the steps of institutions with free wi-fi 
..., to cars, to basements, in a variety of states, countries, time zones." The interaction between the studio and the rest of the campus that used to be an essential feature of the tutor's and students' spatial experiences also disappeared; our mobility is reduced to our moves from one room of our homes to the other. In the physical studio, an interaction between digital media and physical media was generated through the design crits; the tutor was able to share his/her feedbacks about students' projects presented on the screen of a laptop by using a hand drawing sketch on a tracing paper. The virtual/physical interaction was also generated by the tutor giving examples of structural details by showing the details of the physical space of the faculty building or the campus. Now, such kind of interactions has also disappeared.

Mireille Roddier (April 2020) related the loss of physical space in giving design crits remotely with the loss of the critical distance between the work and us:

"... the interface flattens one thing that most requires depth, which is the fluctuating range between foreground and background - not only in space but also in one another's presences; we lose the dynamics between working on a computer and stepping away from it; between pinning a print out on a wall and backing up to observe it; between focusing on one's project and wandering away to a peer's desk to inquire on their progress..." (Mireille Roddier, April 2020)

Remote teaching practices also changed the time allocated to design crits. Normally, the review duration usually extends beyond the scheduled hours in the physical studio. This situation continues in remote teaching for several reasons. In synchronous design crits, the participation percentage of students in scheduled common hours may decrease. Problems such as Internet access, not finding suitable spatial conditions for online design crit for students living with their families, can reduce the participation in synchronous design crit. For those who cannot attend synchronous courses or because of the critiques that cannot be completed during the scheduled review time, tutors usually have to allocate extra time for delivering their feedbacks beyond the scheduled time. In the design critiques given on the digital platforms --such as Zoom, MicrosoftTeams, Skype, etc.-- students seem to be connected to the meeting at the same time. Yet, the students generally prefer not to open their cameras before their review turn; thus, it is not possible to make sure that the students listen to their peers' critiques, as it was the case in the physical studio. This can weaken the possibilities of learning from each other and learning together. On a positive side, the access to experts is strengthened since the external reviewers from different parts of the world are able to participate to design crit sessions. Sharon Haar (April 2020) notes: "At Taubman College, we've been using remote interfaces for a while to bring in national and international visiting critics on a more sustained basis, to organize lunchtime speaker series, and to interact with other schools on studio projects." Thus, remote teaching interfaces may result in new gains for multiplicity of voices in design crits.

The media of architectural expression and representation, which Shaffer (2003) defines as an element of surface structure of design studio pedagogy, are also changing. Acar (2020) underscores the emergence of "simultaneous multi-contact" as a new form of communication in remote design teaching and learning experiences. In the view of Acar (2020), on the one hand this brings responsibility for the tutors, on the other hand it offers new opportunities for the students. The important thing is to discover and apply the tools that will transform the knowledge that the students acquire from the multiple online content, in the direction of their own interest, into an input for the design process.

Remote teaching in the pandemic environment also affected the role of three-dimensional modeling that is an essential tool in studiobased learning: there is a transition from physical models to digital models. Problems arise from the scarcity of materials and the students' inability to go out to get more materials. Students mostly get critiques from 
the digital 2D or 3D drawings of their projects. Although, at a lower rate, some students continue to produce physical models, the interactive and iterative experience of the model making in the studio has disappeared. Alternatively, the students focus more on a 'finalized product' to show to the tutor in order to receive feedbacks on design crit sessions. One of the resultant problems is, the students do not prefer to share anything in-the-making of their design projects. Unless the project is developed to stage the students want to share, the students themselves eliminate the initial stages of the design process. Whereas, the draft models that are used to be produced in the studio were efficient tools for initiating observations and discussions regarding the interim stages of the project. That was an essential feature of formative evaluation that aims to inform the students about how much they have progressed through the design process and to facilitate reflection into their learning processes. A general definition of model is made by Archer (1992, p. 7) as "anything which represents anything else for informational, experimental, evaluative or communication purposes." Model making is an important tool for studio-based learning in design education. In the view of Akalın and Sezal (2009), model making acts not only as a vehicle to communicate with others. It is through the relative accessibility of such concrete modeling that learners have access to their own 'thinking-in-action" (Akalın \& Sezal, 2009, p. 15). Similar to the fact that drawing is related to the act of thinking, model making acts as a form of expression for mental thoughts and imagination (Davies \& Elmer, 2001). What is more, model making allows the designer to test the effectiveness of her design decisions, to evaluate the spatial and/or structural details of a project and to conceive scaling (Parkinson, 2007). In the view of Susannah C. Drake (April 2020), "understanding scale and the relationship of forms loses meaning when translated into photos or videos for screen consumption." In a similar vein, Sharon Haar (April 2020) underscores "the reduction of design to representational space" and the lack of "analog and digital fabrication capacities" of design students in the remote teaching platforms.

\subsection{The "Pedagogical Forms" of Design Studio}

Architectural design studio pedagogy is informed by (1) learner-centered approach as the effective paradigm, (2) the communication / interaction methods between the actors of the learning experience, and (3) the design studio, as a physical and social space, where the learning experience and interaction between these actors takes place. In the process of COVID-19 pandemic, although the actors of the design studio as the tutor and the students are the same, the media through which these actors communicate have changed, and the physical space where they coexist has entirely disappeared. This situation brought forth changes in the pedagogical roles of the tutor and the students as well as the formal and informal interactions between them. In the design studio the pedagogical roles of the tutor inform the ways in which students learn how to design, how they develop design expertise and how they perceive themselves as members of a community of designers (Yorgancioğlu \& Tunali, 2020, p. 22). In the condition that the teaching and learning practices of the pandemic process continues, it is probable that students' ways of learning design, developing design expertise and their self-awareness as members of a community of designers would vary in nature. This change will not happen immediately; it needs to be monitored and analyzed. The effects of the pedagogical change in design education will be best comprehended through the human experiences. Carlo D'Alesio (April 2020) notes: "We will see if - and when - the real digital transformation will come on a deeper, human level."

In the so-called "new normal" of design education, the shift from face-to-face to screento-screen communication the in tutor critiques, peer critiques and jury, brought forth the challenge of "how to communicate meaningfully in this digital space" (Anna Livia Brand, April 2020). The design feedbacks are usually given through digital media that allows drawing sketches on the screen. 
Conventionally, drawing multiple sketches by folding the tracing paper and developing alternative solutions served for the iterative nature of the design process; now, the potential of sketches for generating new ideas are limited to the capability of the user to manage the use of digital media for sketching. What is more, instructors question the tacit dimensions of inter-subjective communication in design feedback based on screen sharing. Alison B. Hirsch (April 2020) underlines the significance of 'the feedback I get from my students' faces and the ability to adjust to the messages their faces and bodies convey" in physical studio, which is replaced by "[t]he small matrix of students' faces, the neutralizing glow of their screens" in Zoom meetings. In a similar vein, David Smiley points to the lack of collaborative experience embedded in inter-subjective communication that used to be generated in desk crits:

\section{"Online teaching seems to flatten both excitement and worry, eliding subtle tensions and side-long glances. The spectrum of communication and connection feels incomplete... desk crits usually consist of groups of students talking with two or three faculty members. This arrangement, meant to acclimate students to collaborative processes and multiple voices, is not well served by current online platforms." (David Smiley, April 2020)}

Alternatively, there are supporters of the idea that the removal of face-to-face communication from design crits would not create negative effects for design education; yet the major challenge would be how to increase the "willingness" of students to participate to remote teaching model (David Heymann, April 2020).

When the learning paradigm embedded in design studio pedagogy is considered, it is evident that learning experience is generated as a social activity as much as it is subjective: "collaboration, language, verbalisation, discussion and dialogue" are the critical elements of the learning process in which the tutors and the students are engaged in the "co- construction of meaning, rather than simple transmission and reception" (Cohen et al., 2010, pp. 36-37). In the design studios, the physical and intellectual dimensions of tutor-student interactions bring about potentials for coconstruction of knowledge and meaning through experience; one of the questions we confront is how much the screen-to-screen communication on online platforms would generate such experiences. This is echoed in the question raised by Nicholas Pevzner (April 2020): "How can this creative, collective space be accessed from home?". Due to the social isolation brought by the COVID-19 pandemic, the disappearance of this social environment became one of the basic problems not only for architectural design education but also for higher education in general. The question raised by Jesse LeCavalier (April 2020) is meaningful in this regard: "How difficult will it be to sustain the university - the society of students and teachers - without the everyday sociality of the campus?"

Nowadays, the students are perhaps able to digitally access much more content than before, and the access channels to the online content and their access duration have increased; however, the fact that they are physically alone at their home can negatively affect the intensity of their active engagement in learning. The stress of being isolated and alone can make it difficult to develop the discipline and concentration needed to initiate and complete the learning process. Some tutors are developing strategies to increase the student participation into the learning process by promoting self-regulated learning in remote teaching practices. Orla Murphy and Emmett Scanlon (April 2020) mention: "We are concerned for students' diminishing agency and control over their education as a result; we place students in a role of peer with their teachers and value a culture of mutual esteem" (Orla Murphy \& Emmett Scanlon, April 2020).

In the design studio, self-regulated or selfdirected learning is also supported through peer review experiences (Grow, 1991; Gray, 2013). Peer review, either initiated by the tutor or among students themselves, encourage students 
to explain their ideas about their peer's projects, reflect on their own experiences, recognize different directions that they had not considered and begin to learn according to which qualities an architectural project can be evaluated (Cowan, 2005). Now, the removal of informal interactions between the students weakened the pedagogical potentials of cooperative and peer learning experiences. Susannah C. Drake (April 2020) notes: "Seeing how classmates experiment, learning from one's peers, getting direct guidance from instructors on the craft and making of models and drawings - these are challenging if not impossible online." What would be alternative strategies in remote teaching model that would foster learning from each other and learning together for architectural design students? Elizabeth Donovan (April 2020) reflects on her attempts to generate "peer-to-peer learning" strategies as part of remote teaching model:

"The current situation has illuminated the
irreplaceable importance of this form of
learning not only in transmitting knowledge
but also in inspiring, motivating, and
supporting students. In an attempt to
emulate these interactions as much as
possible, we are using online platforms
where students can share and interact, and
comment on each other's work. We are
organizing large group discussions (with
about 30 students) and weekly recaps in an
effort to maintain opportunities for the
cross-fertilization of ideas." (Elizabeth
Donovan, April 2020)

Learning by doing, an essential component of studio-based learning is also changing into a new phase. As discussed in the previous section, not only because of the scarcity of materials, but also because of a change in mindset, concrete modeling has been replaced by digital modeling. However, the pedagogic contribution of physical model making to the learning process is evident. The lack of this experience results in weakening of the students' perceptions regarding the 3-dimensionality and scale of architectural space. What is more, their volumetric comprehension is flattened and their discoveries regarding the nature, potentials and constraints of different materials are disturbed. Nicholas Pevzner (April 2020) notes that this situation is even more challenging for 1 st year students "who don't yet have a good handle on the basics of tectonics, representation, and materiality"; he continues to explain: "If the campus shutdown continues next fall, we will need to reassess the foundational tools of design."

The practices of remote teaching also challenge the formative assessment nature of design crit resulting from the 'iterative' nature of the design process. In remote teaching, we can hardly be involved in the students' design processes, since the tutor cannot observe the inprogress status of the projects. Although the digital drawings or physical models are shared by the student on the screen, the student does not continue working within the scheduled online design crit; nor the tutor has the chance to give feedbacks while the students is working. The student focus on an end product to be reviewed rather than sharing the intermediate stages of the design process or design alternatives they developed. Thus, the more intuitive, spontaneous or experimental dimensions of design iterations that were generated by the students while working at the studio are interrupted. Susannah C. Drake (April 2020) explains this situation as follows:

"In my classes, I expect students to sketch
out ideas on trace paper and explore
multiple design options before presenting
finalized plans. It is hard to see and
understand their processes without seeing
the messy iterations - and this is much
harder online. Design is not a linear
process, and I encourage them to embrace
distraction. But these days they don't need
my encouragement for that - and it's hard
to pull them back and get them to
concentrate." (Susannah C. Drake, April
2020)

\subsection{The "Epistemological Principles" of Design Studio}

Due to the lack of embodied encounters in design studio, how the new (digital) communication modes between tutor-student 
and student-student will shape the social interaction between the actors of the design studio and what kind of norms, values and attitudes will develop from them becomes a critical issue. What dynamics will shape the formation of students' identities as designers? What will happen to the studio culture when the physical space of the studio disappears and the manifold interactions taking place at the physical studio environment shift into other forms of digital interactions? Linda C. Samuels (April 2020) asks: "Is it possible to build the same studio culture without the physical places that shape it? And do we want to?" The answers to these questions may give some implications about the epistemological structures of the design studio in the "new normal" of design education.

Gray (2013) notes:

"The environment and personal
assumptions or beliefs about critique proved
to be influential in the actual process of
critique. This interplay of personal agency,
belief, and action interact through the social
construction of normative behaviors and
beliefs-in a shared understanding of what
comprises the habitus of the studio."

The "habitus of the studio," as Gray (2013) underlines it, points not only to the pedagogical practices that shape the signature pedagogy of the design studio model, but also the more implicit references that inform the understandings and behaviors of the tutors and students, the ways that the students learn how to think and act as designers, how they use practice-oriented discourse and how criticize other students' projects by using this discourse. Parnell et al. (2007, p. 136) note: "The crit is not just a place to develop skills and knowledge, but also a place where attitudes are developed." The pedagogical method of design crit encourages the formation of a climate of critical thinking and questioning and of a multiplicity of voices and opinions, which in turn supports the development of a negotiation basis for design learning. The formation of a studio culture is realized through the contribution of both the tutors and the students; it takes a long time and it is passed on over the years. Design studio culture is generated and practiced within the studio environment, and continues informing the practices of the professional community beyond the academic community.

In the views of Anthony (1991) and Crysler (1995), the design studio culture is also "powerladen" by its nature, and it is the "hidden curriculum" what makes it so. The "hidden curriculum" informing the design studio refers to the "values, attitudes, and norms that stem from the social relations of the school and classroom as well as the content of the course" (Dutton, 1991, cited in Abdullaha et al., 2011, p. 28). "Hidden curriculum", not limited to design education, is considered as one of the components of learning process in any educational context, which should be critically considered by instructors and administrators regarding "what their pupils are learning without specifically being taught" (Cohen et al., 2010 , p. 34). These are often learned in the social context of the studio and are shaped through the communication modalities practiced between tutor-student and studentstudent. The "hidden curriculum" also shapes the ways knowledge is selected, organized and disseminated among actors in the design studio. It is being discussed that this can generate tensions of the power relations between the tutor and the student and it can suppress student voice in the studio (Dutton, 1987; Anthony, 1991). In the present conditions, the effect of "hidden curriculum" on the epistemological principles of the design studio is likely to change due to changes in the tools and methods of both tutor-student and the student-student communication and social interaction, as well as due to who will access the information, how the information will be transformed and disseminated.

The epistemological basis of the design studio pedagogy can also be related with the ways of tacit knowing that are embedded in design communication and making. In the view of Carolina Dayer (April 2020) "tacit knowledge, body language, the emotional rhythms and mutual understandings that are animated when we are all together in a room," the elements that influence how the tutor and the students define 
their stances as designers, are likely to "recede to the point of invisibility in distance teaching." In a similar vein, Carlo D'Alesio (April 2020) points to the tacit knowledge embedded in physical human interaction at the design studio, noting: "I realized how important non-verbal communication is in being fast and effective. Take a grunt, a smile, a sketch, a red question mark on a printed technical drawing. These information packages may integrate a thousand words into a couple of seconds." The shift from face-to-face to remote teaching in the pandemic environment brought forth the question of what strategies both the tutors and the students will develop to express themselves, reflection of their ways of thinking and doing. Will the limits and potentials of the digital tools determine the limits and potentials of the representation patterns of individuals about themselves and about the design work they produce? Or, as architects and architect-to-be individuals, will we develop critical and creative solutions to adapt these digital tools used at remote teaching according to the peculiarities of design thinking and doing? It is probable that such critical and creative solutions would derive from our reflection on our experiences, on our ways of doing, while we're doing it.

Another epistemological implication of the ongoing process of remote teaching in design education can be related with the profile of studio tutor as a role model. The tutor is usually a role model for students through her personal stance and appearance, with her knowledge and expertise, and ways of designing. The diverse methods of design feedback (desk critique, jury, etc.) that constitute the signature pedagogy of the studio model generate a ground upon which the effect of tutor's role model is realized. The "one-on-one communication" (Goldschmidt, 2002) between the tutor and the students fuels this process. The remote teaching or distance learning experiences, where communication between tutor and students is always 'mediated' and realized through an 'interface,' changes the tools and reduces the potentials of observing teachers for students. Will new role models emerge for design students who are not able to physically interact with their studio tutors, but at the same time are able to get access to different studio processes throughout the world?

This situation also changes the prevailing hierarchy between the tutor and the students deriving from the way they define their pedagogic identities. Since the design students can simultaneously access various knowledge domains in different digital platforms, they are able to collect, de-construct and re-construct knowledge within their design processes. Thus, the role of tutor will be more of a "facilitator" (Belluigi, 2016) than a "source of knowledge" or "source of authority" (Goldschmidt, 2002). The "asymmetrical power relations" between the tutor and the students (Webster, 2007) will probably get softer, both in the weekly design feedback sessions and in the jury sessions. Philip Ursprung (April 2020) raises the questions of whether meeting online in diverse digital platforms could "prefigure a new way to meet" and "open up the hierarchies that we have established in our education over the years." We need to analyze the teaching and learning experiences we derive from remote teaching processes, and then, we will be able to generate more information on the results from this analysis, which will take time.

\section{Conclusion}

The rapid transition from face-to-face education to remote teaching because of the COVID-19 pandemic brought with it a process of challenge and experiment for us, as studio tutors, who are firmly committed to the tools and methods of the mainstream design pedagogy. While experiencing this process, the change in the environment (space), tools and methods we are accustomed to, not only caused an anxiety and uncertainty about how to implement the practices we have been doing for years, but also forced us to adjust ourselves both as tutors and students to the conditions defined as the "new normal" of design education. That is why the ongoing process is mostly defined as "emergency remote teaching."

This article focused on the problems experienced within the transition to remote teaching, the new needs that arise, as well as an awareness of the lack of key elements of the physical studio environment: what was 
important and why was important in traditional design studio pedagogy. The study was based on a critical re-reading mostly of narrative surveys on the teaching and learning experiences at pandemic environment. It is aimed to re-contextualize the emerging issues in "new normal" conditions into a general framework on the "surface structures", "pedagogical forms" and "epistemological principles" elements of the design studio pedagogy, adapted from the theoretical framework of Shaffer (2003).

It is revealed in the article that, the current situation that is common all over the world within the scope of the COVID-19 pandemic, on the one hand, has opened the ways for us to test "new" tools, methods and experiences of teaching and learning, and on the other hand, allowed us to better understand the potentials and well-functioning aspects of the "existing" pedagogical models. Therefore, instead of reading this situation as a process in which "new" pedagogical models will replace the "old" studio-based learning model, we have better consider it as an opportunity to reflect upon the challenges and potentials of both digital tools/platforms and traditions design studio model, and to initiate experiments for the development of a new approach that would support each other and move in parallel.

In order to do that, it will be necessary to look at the outputs of the process we are already experiencing, collect data by research and look at the findings from the analysis of these data. The ongoing process can hardly be defined as a paradigm shift in design education due to the lack of sufficient experiences and data. Future research needs to focus on the effects of changing pedagogical practices on the dimension of the 'human learning', which in turn have implications for the epistemology of design education. It is evident that the learning styles, situations and environments are closely related to each other. As underlined by Gray (2016, p. 272), a "holistic view of the studio involves a fusion of physical or virtual learning environment, instructional experience, and enculturation into a discipline." If the teaching and learning practices are to be designed according to new tools, this should be done after redefining learning and teaching models in design education. What is more, new strategies need to be developed in order to respond to the ways of "tacit knowing," which cannot be taught directly. In the condition that the current situation of remote teaching and learning is reduced to a 'technology-driven' paradigm change, the limits of the digital tools we use will begin to determine the limits of teaching and learning experiences both for the tutors and the students. This will weaken the potentials of the intuitive, spontaneous or experimental dimensions of design learning that are embedded in design education.

\section{References}

Abdullaha, N. A. G., Behb, S. C., Tahirb, M. M., Che Anib, A. I., \& Tawilb, N. M. (2011). Architecture design studio culture and learning spaces: a holistic approach to the design and planning of learning facilities. Procedia Social and Behavioral Sciences, 15, 27-32. doi:10.1016/j.sbspro.2011.03.044

Acar, A. (2020). Birinci sınıf mimarlık eğitimi için çevirimiçi izdüşümler. $X X I$, 1-18. Retrieved from: https://xxi.com.tr/i/birincisinif-mimarlik-egitimi-icin-cevrimici

Akalın, A., \& Sezal, I. (2009). The importance of conceptual and concrete modelling in architectural design education. JADE, 28(1), 14-24. doi: 10.1111/j.1476-8070.2009.01589.x

Anthony, K. H. (1991). Design juries on trial: The renaissance of the design studio. New York: Van Nostrand Reinhold.

Archer, B. (1992). As complex as ABC. In P. Roberts, B. Archer, \& K. Baynes (Eds.). Design: Occasional Paper No. 1, Modeling: The language of designing (pp. 7-11). Loughborough: Loughborough University of Technology.

Cohen, L., Manion, L., Morrison, K., \& Wyse, D. (Eds.). (2010, fist published in 1977). $A$ Guide to teaching practice (5th ed.). London \& New York: Routledge. 
Cowan, J. (2005), 'Evaluation and feedback in architectural education', in D. Nicol and S. Pilling (eds.) Changing architectural education: Towards a new professionalism (pp. 236-244). London and New York: Taylor \& Francis Group.

Crowther, P. (2013). Understanding the signature pedagogy of the design studio and the opportunities for its technological enhancement. Journal of Learning Design, 6(3), Special Issue: Design Education, 18-28. doi: $10.5204 /$ jld.v6i3.155

Crysler, C. G. (1995). Critical pedagogy and architectural education. Journal of Architectural Education, 48(4), 208-217.

Davies, T., \& Elmer, R. (2001). Learning in design and technology: the impact of social and cultural influences on modeling. Journal of Technology and Design Education, 11(2), 16380.

Dutton, T. A. (1987). Design and studio pedagogy. Journal of Architectural Education, 41(1), 16-25.

Dutton, T. A. (1991). The hidden curriculum and the design studio. Voices in Architectural Education: cultural politics and pedagogy. ( $p p$. 165-194), New York: Bergin and Garvey.

Field Notes on Pandemic Teaching: 1. (April 2020). Reinhold Martin, Susan PiedmontPalladino, Brent Sturlaugson, Barbara Penner, Harriet Harriss, Judith Rodenbeck, Sandy Isenstadt, Anna Livia Brand, Iman Ansari, Hélène Frichot, Brett Milligan, Places Journal. Retrieved May 12, 2020, from https://placesjournal.org/article/field-notes-onpandemic-teaching-1/)

Field Notes on Pandemic Teaching: 2. (April 2020). Simon Sadler, Patricia Morton, Richard J. Williams, Fred Scharmen, Clare Lyster, Marshall Brown, Jeffrey Hou, Sarah Lappin, Jonathan Massey, David Heymann, Frances Richard, Places Journal. Retrieved May 12, 2020 , https://placesjournal.org/article/field-notes-onpandemic-teaching-2/)

Field Notes on Pandemic Teaching: 3. (April 2020). Johan Pries, Andrew Herscher, Hugh Campbell, Shannon Mattern, Erin Moore, Rasmus Hansen, Frederick Steiner, Mireille Roddier, Mira Schor, Shelly Silver, Charles Davis, Philip Ursprung, Places Journal. Retrieved from May 12, 2020, from https://placesjournal.org/article/field-notes-onpandemic-teaching-3/)

Field Notes on Pandemic Teaching: 4. (April 2020). David Smiley, Alison Hirsch, Iñaki Alday, Kim Anno, Greg Lindquist, Keith Eggener, Linda C. Samuels, Arda İnceoğlu, Lori Brown, Marc J. Neveu, Kristi Cheramie, Sharon Haar, Places Journal. Retrieved May 12, 2020, from https://placesjournal.org/article/field-notes-onpandemic-teaching-4/>

Field Notes on Pandemic Teaching: 5. (April 2020). Orla Murphy \& Emmett Scanlon, Liska Chan, Derek Hoeferlin, Peggy Deamer, Yuko Uchikawa, Hugh Raffles, Manuel Shvartzberg Carrió, Sarah Rottenberg, Germane Barnes, Jesse LeCavalier, Susannah Drake, Annmarie Adams, Carolina Dayer, Places Journal. Retrieved May 12, 2020, from https://placesjournal.org/article/field-notes-onpandemic-teaching-5/>

Field Notes on Pandemic Teaching: 6. (April 2020). Kadambari Baxi, Matias del Campo, Fadi Masoud, Renée Cheng, Elizabeth Donovan, Carl Smith, Dana Tomlin, Aaron Cayer, Delia Mellis, Huda Tayob, G. Pelin Sarıoğlu Erdoğdu, Nicholas Pevzner, Robin Tremblay-McGaw, Billy Fleming, Places Journal. Retrieved May 12, 2020, from https://placesjournal.org/article/field-notes-onpandemic-teaching-6/>

Gray, C. M. (May 2013). 'Informal peer critique and the negotiation of habitus in a design studio', in J. B. Reitan, P. Lloyd, E. Bohemia, L. M. Nielsen, I. Digranes and E. Lutnæs (Eds.), Proceedings of DRS // CUMULUS 2013, 2nd International Conference for Design Education 
Researchers Oslo, 14-17 May 2013, pp. 702714.

Gray, C. M. (2016). Emergent views of studio. In E. Boling, R. A. Schwier, C. M. Gray, K. M. Smith \& K. Campbell (Eds.), Studio teaching in higher education (pp. 271-280). New York and London: Routledge Press.

Grow, G. O. (1991). Teaching learners to be self-directed. Adult Education Quarterly, 41(3), 125-149.

How architecture students and educators are optimizing their work environments at home. (2020, April 3). Retrieved May 12, 2020, from https://archinect.com/news/article/150192041/ how-architecture-students-and-educators-areoptimizing-their-work-environments-at-home

How architecture students and educators are handling the transition to online coursework. (2020, March 26). Retrieved May 12, 2020, from

https://archinect.com/news/article/150190812/ how-architecture-students-and-educators-arehandling-the-transition-to-online-coursework

How COVID-19 is affecting architecture students and educators on an emotional level. (2020, March 31). Retrieved May 12, 2020, from

https://archinect.com/news/article/150191482/ how-covid-19-is-affecting-architecturestudents-and-educators-on-an-emotional-level

Parnell, R., Sara, R., Doidge, C, \& Parsons, M. (Eds.). (2007, first published in 2000). The crit. An architecture student's handbook (2nd ed.). London \& New York: Routledge.

Parkinson, E. (2007). Practical modeling and hypothesis testing in primary design and technology education. International Journal of Technology and Design Education, 17(3), 23351.

Shaffer, D. W. (2003). Portrait of the Oxford Design Studio: An ethnography of design pedagogy (WCER Working Paper No. 200311). Madison, WI: University of Wisconsin-
Madison, Wisconsin Center for Educational Research.

Shulman, L. S. (2005). Signature pedagogies in the professions. Daedalus, 134(3), 52-59.

The New Normal: Educating in times of Corona. An interview with Carlo D'Alesio. (2020, April 30). Retrieved May 10, 2020, from https://warm-white.com/an-interview-withcarlo-dalesio/

The Coming Disruption. (2020, May 11). Retrieved May 15, 2020, from https://nymag.com/intelligencer/2020/05/scottgalloway-future-of-

college.html?utm_medium=s1\&utm_campaign $=$ nym $\&$ utm $\_$source $=$fb \& fbclid $=$IwAR $0 \mathrm{vVLD}$ G2KEDa5fot7V56YIYQXQVbQ7U56vciziOI SNpSxWYi3--7--aNU0

Yorgancioğlu, D., \& Tunalı, S. (April 2020). Changing pedagogic identities of tutors and students in the design studio: Case study of desk and peer critiques. Art, Design \& Communication in Higher Education (ADCHE), 19 (1), 19-32. doi: 10.1386/adch_00011_1 